\title{
Pro-Angiogenic Mediators as Targets for Chemotherapy of Colorectal Carcinoma
}

\author{
N. M. Abdel-Hamid ${ }^{1, *}$, M. Farid ${ }^{2}$, A. Eldemeri ${ }^{3}$, M. Atwa ${ }^{4}$, N. Anbar ${ }^{5}$ \\ ${ }^{1}$ Nabil Mohie Abdel-Hamid, Departments of Biochemistry, College of Pharmacy, Minia University \\ ${ }^{2}$ Mohamed Farid, General Surgery \\ ${ }^{3}$ Ahmed Hasan Eldemiri, Medical Oncology \\ ${ }^{4}$ Mohamed Atwa, Clinical Pathology, Faculty of ${ }^{2,3,4}$ Medicine \\ ${ }^{5}$ Nahla Hamed Anbar, Emergency Hospital, Mansoura University, Egypt
}

\begin{abstract}
Purpose Angiogenesis and chronic inflammation are codependent in pathogenesis of colorectal carcinoma (CRC). We aim to assess whether vascular endothelial growth factor (VEGF), nitric oxide (NO) and total lipase (TL) activity being contributors to angiogenesis, are targets for CRC chemotherapy. Methods we enrolled 60 subjects, 20 volunteers (10 males and 10 females) were assigned as control (group I). Forty CRC patients, 20 locally advanced (group II), subjected to surgery and chemotherapy (5-fluorouracil $\left(5-\mathrm{FU}, 425 \mathrm{mg} / \mathrm{m}^{2}\right)$ plus leucovorin $(\mathrm{LV}, 20 \mathrm{mg} / \mathrm{m} 2)$, IV, daily for 5 consecutive days, repeated every 3 to 5 weeks for 6 courses). The other 20 patients, were metastatic, (group III), followed up, given only adjuvant chemotherapy. Results Serum carcino embryonic antigen (CEA), cancer antigen (CA19.9), VEGF, NO concentrations and TL activity were significantly elevated in CRC compared to control and in Gp III compared to Gp II patients, but were down-regulated by chemotherapy. VEGF, NO and TL helped in diagnosis and follow up of CRC, although they were not returned to reference intervals. In conclusion, the response to chemotherapy of VEGF, NO and TL substantiates an anti-angiogenic potential in controlling CRC. AFP level was not changed in secondary metastatic hepatocellular carcinoma (HCC), seemingly, it rises only in primary HCCs.
\end{abstract}

Keywords Angiogenesis, Chemotherapy, CRC, Metastasis, NO, Total lipase, VEGF

\section{Introduction}

Colorectal cancer (CRC) is one of the major causes of cancer death worldwide, accounting for more than 150000 new cases, 55000 deaths in the United States and more than 100000 mortalities per year in Europe. The incidence of CRC in Egypt ranges from 2 to 6\%[1].There is an increasing risk among those who have first degree relatives with CRC, constituting up to $20 \%$ of all patients with $\mathrm{CRC}[2]$.The degree of personal risk relates to family history and age of affected relatives[3]. Increased age was associated with increased risk of advanced colonic neoplasia[4]. Moreover, excessive weight and abdominal obesity were found to be risk indicators in men and women[5]. Generally, women have more favorable prognosis than men. The relation between gender and survival from CRC was complex and appeared to be related to differences in tumor stage and therapeutic modality[6].Treatment of CRC is greatly dependent on onset and stage of the disease. It always ranges from (1) surgical management by removal of the primary

* Corresponding author:

nabilmohie@yahoo.com (N. M. Abdel-Hamid)

Published online at http://journal.sapub.org/ajmms

Copyright (C) 2011 Scientific \& Academic Publishing. All Rights Reserved tumor with adequate safety margin, (2) treatment of the draining lymphatics, and (3) restoration of function. Appropriate adjuvant therapies can enhance local control, reduce systemic recurrence and increase organ preservation[7]. Approximately $6 \%$ to $10 \%$ of rectal cancers are locally advanced and require extensive surgery for complete tumor extirpation[8].

Chemotherapy is usually prescribed to eradicate micrometastasis sensitive to cytotoxic therapy. The standard treatment of metastatic colorectal cancer is a combination of 5-fluorouracil/folinic acid with irinotecan or oxaliplatin-based chemotherapy. 5-flourouracil (5-FU) is given to patients with Dukes B, C stage in combination with radiotherapy to secure local recurrence and distant metastasis[9]. Metastasis of CRC to other extracolonic organs, especially liver is always faced among patients with long standing disease. Diagnosis of metastasis is made by both histological and serological investigations. Alpha fetoprotein (AFP) is always used to pursue or exclude hepatic metastasis. AFP is a normal fetal serum protein synthesized by the liver, yolk sac and falls to an undetectable level after birth. The primary malignancies associated with AFP elevations are HCC, linked with chronic infections as hepatitis $\mathrm{B}$ and $\mathrm{C}$ viruses and with cirrhosis from various causes. AFP elevation is common in Africa, where HCC is endemic, and is useful in 
screening purposes. It can be used to determine the most appropriate treatment for liver cancer and to follow patients after curative surgery or other treatment[10]. AFP is elevated in testicular germ cell tumors containing embryonal or endodermal sinus elements. It is a definitive positive marker in indicating relapse or response to treatment[11]. Tumor angiogenesis is the proliferation of a network of blood vessels that penetrate into cancerous growths, supplying nutrients, oxygen and removing waste products. It starts concomitantly with cancerous tumor cells sending signals to surrounding normal host tissue. This signaling activates certain genes in host tissue, in turn, make proteins to encourage growth of new vessels[12].

However, controllable angiogenesis occurs in healthy body for healing wounds and restoring blood flow to tissues after injury. In females, angiogenesis also occurs during the monthly reproductive cycle to rebuild the uterus lining, to mature the egg during ovulation and during pregnancy to build placenta, favoring maternal- fetal circulation[13]. Trials to inhibit angiogenesis as means of controlling growth and spread of cancer cells began before $39 \mathrm{yr}$ ago[14]. Numerous angiogenic growth factors were targeted with modern drugs and have been identified in large bowel tumors. These included, vascular endothelial growth factor (VEGF), platelet-derived endothelial cell growth factor (PD-ECGF), basic fibroblast growth factor (bFGF), platelet-derived growth factor (PDGF), insulin-like growth factors (IGFs), angiogenin, thrombospondin, angiopoeitins, and integrins [15].

Binding to VEGF receptor-2 (VEGFR-2) starts a tyrosine kinase signaling cascade that stimulates NO expression[16]. Inducible nitric oxide synthase (iNOS) is an enzyme catalyzes NO production, found to be over-expressed in chronic inflammatory diseases and various types of cancer[17]. NO is an important regulatory molecule in inflammatory response, cancer development and endogenous mutagenenesis[18,19], angiogenic factor[20], an enhancer of protooncogene expression[21,22] and an inhibitor of apoptosis[23]. Lipase is a water-soluble enzyme that catalyzes the hydrolysis of ester bonds in water insoluble, lipid substrates[24]. It exerts dual functionality: anti-inflammatory, through enhancing remnant lipoprotein catabolism and pro-inflammatory through alteration in lipid metabolism and induction of inflammatory cytokines[25]. It was implicated in colorectal carcinogenesis, being engaged in mucosal lipid metabolism. Thus, lipase activity was reported to be increased in the colorectal mucosa affecting lipid metabolism within the tumor tissue[26]. Angiogenesis is a target of some new drugs used as adjuvant for chemotherapy. These drugs may be expensive, or in many developing countries, not yet utilized, and conventional chemotherapies still the cornerstone in cancer management in public hospitals. Most studies on angiogenesis relied on VEGF. NO and lipase are always missing among angiogenic stimulators in most -if not all- studies on angiogenesis inhibition.

The present work aimed at studying the contribution of angiogenesis in CRC pathogenesis, recurrence and metastasis among groups from Mansura city, staged according to Duke's principle. In addition, exploring a possible effect of common chemotherapy on angiogenesis, depending on three relevant parameters, serum VEGF and NO and total lipase levels (TL), to monitor CRC progression along with carcinoembryonic antigen (CEA), carbohydrate (carcinogenic) antigen (CA 19.9) and AFP serum levels as diagnostic and prognosticators. Tissue samples from both colon and liver were examined before surgical intervention for cancer staging.

\section{Materials and methods}

\subsection{Patients}

This study was carried on 60 subjects; 40 patients with histopathologically confirmed CRC (classified into 2 groups, 20 patients (stages B \& C) according to Dukes' staging[27], 11 males and 9 females of age range $41.2 \pm 12.9$ years (mean $\pm \mathrm{SD}$, assigned as locally advanced CRC (Group II). Patients of this group were subjected to elective surgery and adjuvant chemotherapy. The third group, assigned as metastatic (group III), consisted of 20 CRC patients of stage D, 10 males and 10 females, their mean age was $48.3 \pm 11.2$ years, patients of this group were followed up and given only adjuvant chemotherapy, adapted according to Mayo Clinic regime (5-fluorouracil, $425 \mathrm{mg} / \mathrm{m} 2$ plus leucovorin $20 \mathrm{mg} / \mathrm{m} 2$, by rapid IV bolus, daily for 5 consecutive days every 3 to 4 weeks, repeated for 6 courses[28]. Body surface area (BSA) in $\mathrm{m} 2$ was calculated from the following formula:

$$
\mathrm{BSA}=(\mathrm{W} 0.425 \times \mathrm{H} 0.725) \times 0.007184 .
$$

(W) represents weight in kilograms and $(\mathrm{H})$, height in centimeters $[29,30]$. The studied parameters were compared to that of normal control (group I), consisted of 20 volunteers (10 males and 10 females, of mean age, $49.4 \pm 18.2$ years, from volunteer nursing staff), at Surgery and Nuclear Medicine Departments, Mansoura University Hospitals, Egypt, between January 2007 and January 2009. Written consents were taken from all participants. Thorough history including age, sex, rectal bleeding, abdominal distention, constipation, special habits, history of previous colorectal disease or surgery, clinical examination and manifestations of intestinal obstruction, general, abdomino-pelvic and rectal examination were done. Barium enema, abdominal ultrasound and preoperative colonoscopy, biopsy for histological examination were achieved for differential diagnosis and Dukes' staging, were conducted. These information were archived in patient files at the Department Registration Office. Among the studied CRC groups, male to female ratio was $54.3 \% / 45.7 \%$. Fasting blood samples were withdrawn from patients and control, separated sera were kept for assays. Participated patients shown as post-treatment subjects, others, changed setting of follow-up. Figures show the clinical findings of presented cases, (Figure 1-3), in addition to histological examination of both colon and liver of 
the selected groups before surgical intervention (Figure 4):

\subsection{Methods}

Histological examination of pre-operative tissue samples were done after hematoxylin and eosin (H\&E) staining. Serum CEA and CA19.9 were determined by automatic Roche Elecsys 2010, Switzerland, based on electrochemically generated chemiluminiscence[31]. AFP was determined by Sandwich ELISA, Boehringer, Germany[32]. Se- rum VEGF level was made by Sandwich enzyme immunoassay technique (R \& D Systems Inc., MN, USA) according to the method of Sheng et al.[33]. Nitric Oxide (NO) was assayed by colorimetric method using kit group of Oxis International Inc, Portland, OR, USA, according to the method of Miranda et. al,[34]. Serum total lipase activity was determined by kits purchased from Genzyme Diagnostic, Inc, Canada and the manufacturer's instructions were followed.

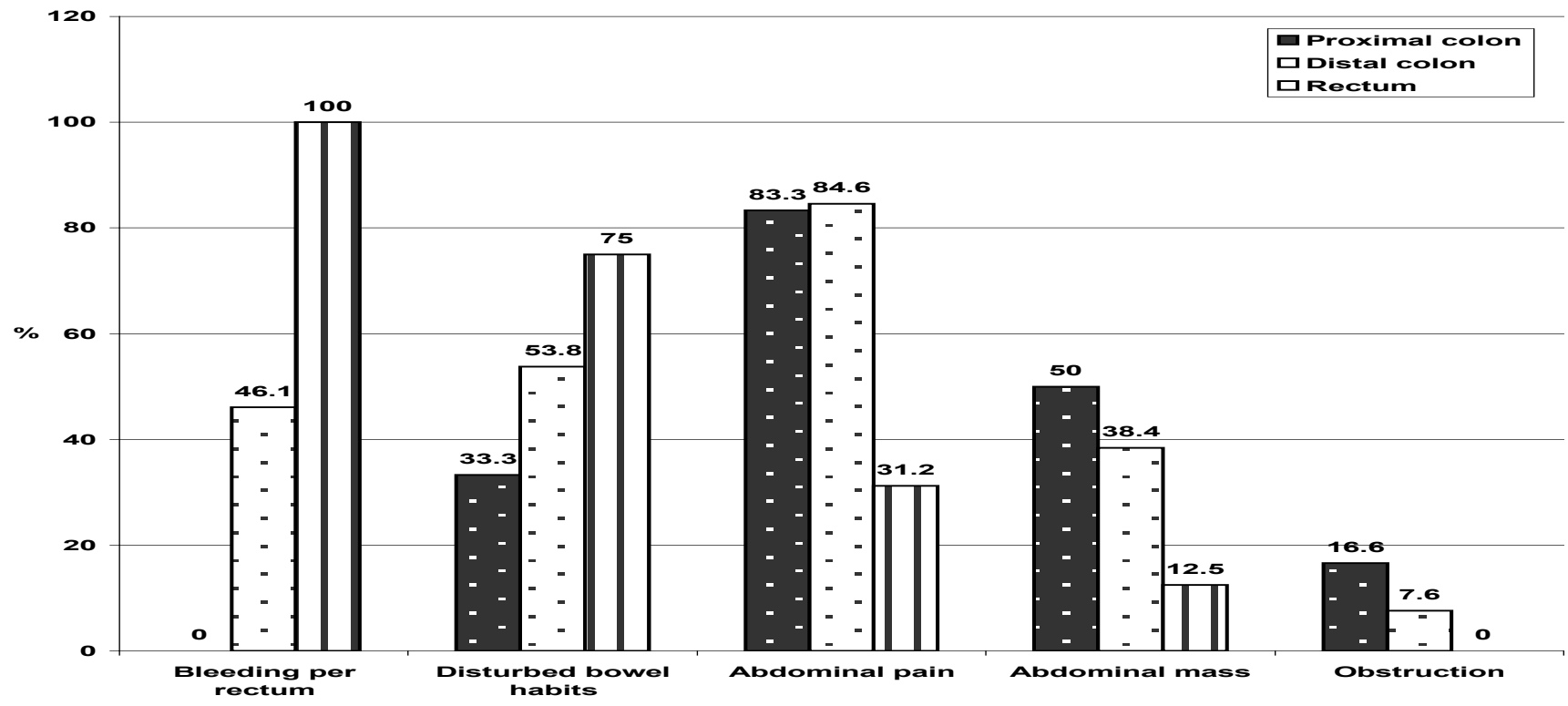

Figure 1. Clinical data of CRC patients. Numbers of recruited patients (Proximal colon: 10, Distal colon:15, Rectum:15), percentages are among each group .

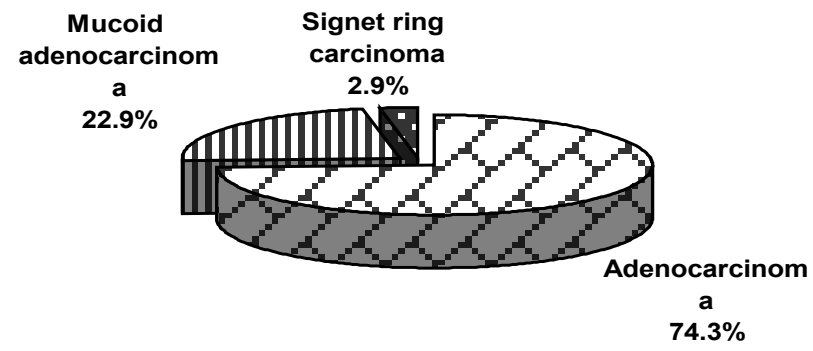

Figure 2. Pathological forms among CRC patients.

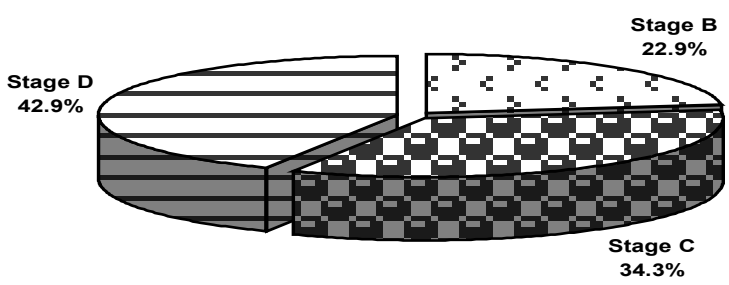

Figure 3. Duckes stages of CRC patients.

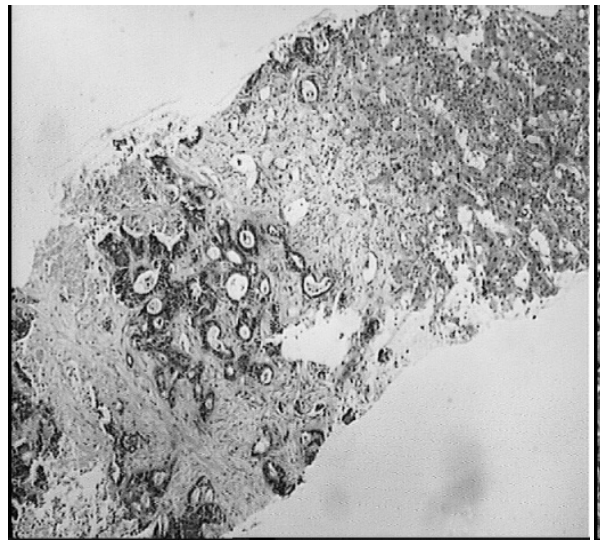

Metastatic adenocarcinoma in the liver, grade D. $x 100$

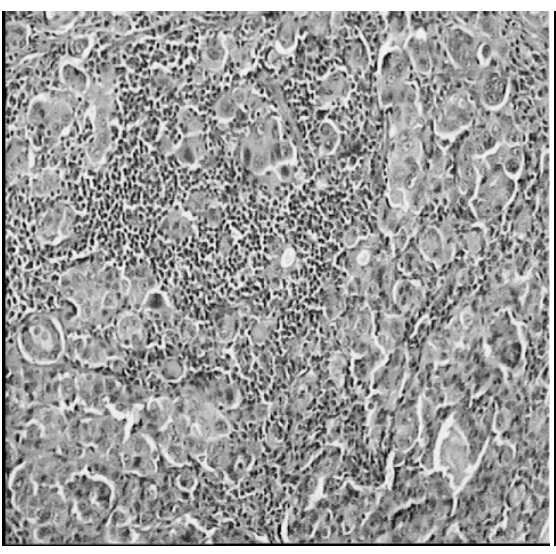

Metastatic adenocarcinoma in lymph node, grade C. x200

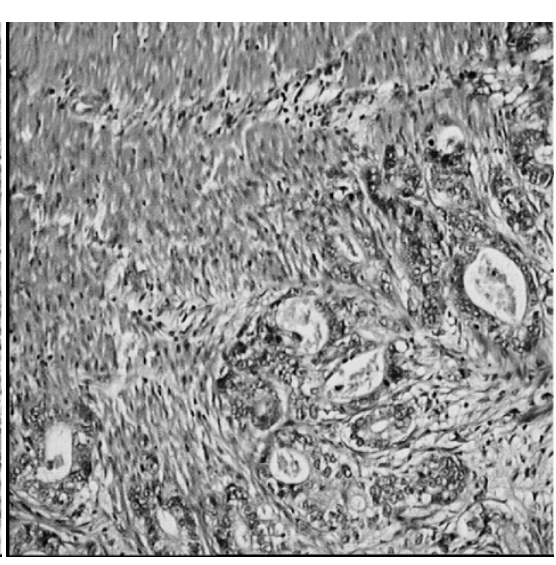

Tumor infiltrate muscle, grade B1. $\mathrm{x} 200$

Figure 4. Histological staging of CRC patients, showing both locally advanced and metastatic invasion among studied cases. 


\subsection{Statistical analysis}

The data were expressed as mean \pm SD. Statistical significance was examined by one-way analysis of variance (ANOVA) using SPSS program. $\mathrm{P}$ values less than 0.05 were assumed to be statistically significant.

\subsection{Ethical approval}

Ethical approval for the study was obtained from Mansura University Research Ethics Committee.

Table 1. Serum levels of CEA, CA 19.9 and AFP in CRC patients, pre and post chemotherapy, compared to control (Values are expressed as Mean \pm SD)

\begin{tabular}{|c|c|c|c|}
\hline Group & CEA (ng/dl) & $\begin{array}{c}\text { CA } 19.9 \\
(n g / d l)\end{array}$ & $\begin{array}{c}\text { AFP } \\
(\mathbf{n g} / \mathbf{m l})\end{array}$ \\
\hline $\begin{array}{l}\text { Control subjects } \\
(\mathrm{n}=20)\end{array}$ & $2.44 \pm 0.27$ & $8.6 \pm 0.01$ & $5.93 \pm 0.60$ \\
\hline $\begin{array}{l}\text { CRC Patients } \\
(\mathrm{n}=40) . \text { (Data of } \\
\text { both groups before } \\
\text { treatment are pooled) }\end{array}$ & $40.72^{* *} \pm 3.60$ & $30.0^{* *} \pm 2.52$ & $7.34 \pm 0.57$ \\
\hline $\begin{array}{l}\text { Pretreated group II } \\
(\mathrm{n}=20)\end{array}$ & $34.72^{* *} \pm 3.92$ & $23.45^{* *} \pm 2.43$ & $7.76 \pm 0.64$ \\
\hline $\begin{array}{l}\text { Pretreated group III } \\
(\mathrm{n}=20)\end{array}$ & $48.34^{\delta^{* *}} \pm 6.07$ & $38.30^{* * \&} \pm 3.93$ & $7.64 \pm 0.99$ \\
\hline $\begin{array}{l}\text { Post-treated group II } \\
(n=20)\end{array}$ & $14.47^{\& \&} \pm 1.76$ & $13.57^{\& \&} \pm 1.55$ & $7.48 \pm 0.71$ \\
\hline $\begin{array}{l}\text { Post-treated group III } \\
(n=20)\end{array}$ & $26.05^{\$ \#} \pm 4.77$ & $29.95 \pm 4.03^{\$ \$}$ & $7.16 \pm 0.95$ \\
\hline
\end{tabular}

Table 2. Serum levels of VEGF, NO and TL activity in CRC patients, pre and post chemotherapy, compared to control (Values are expressed as Mean \pm SD).

\begin{tabular}{|c|c|c|c|}
\hline Group & VEGF (pg/ml) & $\mathrm{NO}(\mu \mathrm{mol} / \mathrm{l})$ & $\begin{array}{c}\text { Total lipase } \\
\text { (U/I) }\end{array}$ \\
\hline $\begin{array}{l}\text { Control sub- } \\
\text { jects }(n=20)\end{array}$ & $169.55 \pm 10$ & $7.15 \pm 0.37$ & $33.53 \pm 1.55$ \\
\hline $\begin{array}{l}\text { CRC Patients } \\
(\mathrm{n}=40) \\
\text { (Data of both } \\
\text { groups before } \\
\text { treatment are } \\
\text { pooled) }\end{array}$ & $614.94^{* *} \pm 51.28$ & $18.26^{* *} \pm 1.13$ & $42.67 \pm 2.21^{* *}$ \\
\hline $\begin{array}{l}\text { Pretreated } \\
\text { group II }(\mathrm{n}= \\
20)\end{array}$ & $476.47^{* *} \pm 45.78$ & $16.97^{* *} \pm 1.75$ & $40.21 \pm 1.82^{* *}$ \\
\hline $\begin{array}{l}\text { Pretreated } \\
\text { group III }(n= \\
20)\end{array}$ & $790.33^{* *} \&_{ \pm 81.89}$ & $19.97^{* *} \&_{ \pm 1.0}$ & $44.81 \pm 3.80^{* * \& \&}$ \\
\hline $\begin{array}{l}\text { Post-treated } \\
\text { group II }(n= \\
20)\end{array}$ & $220.78^{\& \&} \pm 21.11$ & $10.93^{\&} \pm 0.97$ & $37.29 \pm 1.79^{* * \& \&}$ \\
\hline $\begin{array}{l}\text { Post-treated } \\
\text { group III } \\
(\mathrm{n}=20)\end{array}$ & $499.80 \pm 47.52^{\$ \$ \#}$ & $14.61 \pm 1.80^{\text {S\# }}$ & $34.26 \pm 2.43^{\# \#}$ \\
\hline
\end{tabular}

In Tables 1, 2: ${ }^{* *}$ Highly significant increase $(\mathrm{P}<0.01)$ when compared to control subjects.

Significant increase $(\mathrm{P}<0.05)$ when compared to pretreated group II patients.

${ }^{\&}$ Highly significant decrease $(\mathrm{P}<0.001)$ when compared to pretreated group II.

Significant decrease $(\mathrm{P}<0.05)$ when compared to pretreated group III patients.

Highly significant decrease $(\mathrm{P}<0.001)$ when compared to pretreated group III patients.

Significant increase $(\mathrm{P}<0.05)$ when compared to post-treated group II patients.

$\$ \$$ Highly significant increase when compared to post-treated group II (P < $0.001)$.

\subsection{Results}

Histological examination showed malignant alterations in colon tissue and graded as B1 (lymph node) and C (muscular) infiltration, being locally advanced, while graded D patients showed metastatic liver cancer (Figure. 4).

Serum levels of CEA and CA 19.9 were significantly higher among CRC patients, higher values in group III rather than group II individuals. These parameters were significantly depressed after treatment in both groups II and III although a failure to reach normal control values is seen. AFP values in CRC groups were ns elevated than control values, chemotherapy also ns depressed its values (Table1). Both VEGF, NO and TL were significantly elevated in CRC individuals than normal control. The three parameters were significantly higher in metastatic than locally advanced CRC individuals and healthy controls. Chemotherapy although significantly decreased theses parameters, only TL activity was near to normal in metastatic individuals, while both VEGF and NO were not(Table 2).

\section{Discussion}

Angiogenesis is a pre-requisite for tumor growth and metastasis. Development of cancer consists of multiple, sequential and interrelated steps that lead to generation of autonomous clone with aggressive growth potential. Then, the stroma must be vascularized to support continued growth and spread[35]. VEGF expression is significantly correlated with lymph node metastasis and clinical stages of $\mathrm{CRC}[36]$. Extensive studies on inhibition of angiogenesis as a new way to inhibit cancer, are going on. Bevacizumab (a new monoclonal antibody against VEGF) was selectively used, combined with common chemotherapeutic protocols, this greatly increased survival rates and improved outcomes[37,38].

In the present work, CEA and CA19.9 were used as biochemical markers for judging CRC, AFP for judging liver cancer metastasis in addition to demographic, endoscopic, histological data (Figure. 1-4). These tumor markers were significantly higher in all CRC samples, showing higher elevations in metastatic subjects. These results are in agreement with that of Wang et al.[39], who reported that CEA is associated to gastrointestinal cancer, produced abundantly in CRC tissues. Increased CEA level in group III rather than II is in accordance with some previous observations[39,40,41], noticed that CEA level is increased with stage and metastasis of tumor. CEA is expressed in normal mucosal cells and over-expressed in adenocarcinoma, especially CRC[42]. Elevated CA19.9 is in agreement with results reported by Duffy et al.[43], who reported that it is frequently increased in sera of patients with colorectal cancer. Increased CA19.9 level with tumor stage is also in agreement with results of Grotowski et al.[41], Wang et al.[44], who reported that CA19.9 level and sensitivity are increased with increasing Duke's stage.

5-FU/LV significantly down-regulated CEA and CA19.9 
in locally advanced and metastatic patients than pretreatment values. Although these figures couldn't be restored to normal CRC-free values, clinical status of patients was moderately improved. These results were previously registered by Gholam and co-authors[45].AFP didn't show significant variations in all studied subjects in comparison to control healthy group. This possibly means that AFP appears only after longer period of metastasis into liver from an extrahepatic donor organ and that the examined patients haven't AFP colon cancer producers[46]. VEGF is the most important cytokine involved in neo-angiogenesis which is of crucial importance for CRC[47]. It has been demonstrated that increased vessel counts in tumors are associated with higher risk of metastasis in various types of cancers, including CRC[48].

In our study, VEGF was significantly higher in all CRC samples, showing more significant elevations in metastasis (group III than group II) patients. These results indicate that VEGF expression is increased with advancing Duke's stages, coincided with Galizia et al.[49]. Lee et al.[50] added that, VEGF expression was increased with progression of CRC stages and patients with highest VEGF expression had significantly poorer prognosis, earlier recurrence and death than those with lower levels. The high VEGF expression, correlated with Duke's stages and presence of distant metastasis could be explained by high molecular alterations in advanced CRC[51].

5-FU/LV significantly decreased VEGF levels in locally advanced and metastatic groups. Actually, studies of the impact of 5-FU/LV on VEGF levels were very sparse. Most studies in this respect relied on clinical symptoms relevant to angiogenesis without evaluation of this pro-angiogenic factor. Some studies tried bivacizumab with 5 -FU/LV to pursue antiangiogenic potential of this new drug, without assessing VEGF values[52]. Additionally, in vitro studies showed that 5-FU based drugs, given alone, could inhibit angiogenesis[53,54]. Inversely, low doses of 5-FU stimulated angiogenesis, meaning that only cytotoxic doses can inhibit angiogenesis[55].

On the other hand, inducible NO(iNOS) has been elevated in gastric metaplasia[56], chronic gastritis[57], hepatocytes in viral hepatitis[58], cholangiocytes in primary sclerosing cholangitis[59] and colonocytes in inflammatory bowel disease[60]. Production of NO may promote tumor growth by stimulating angiogenesis[61], increasing vascular permeability and suppressing the immune response[62]. Our study showed a highly significant increase in serum NO level in CRC patients, group II and III than control. Fantapie et al.[63] reported that NO was over-expressed in tumor tissue compared to normal mucosa of CRC patients. Hao et al.[64] registered that iNOS level was increased in the tumor tissue two-folds when compared to normal colon mucosa. Our results revealed more significant increase in serum NO level in those with metastasis when compared to pretreated group II patients. This result agreed with that of Jenkins and colleagues[20], who reported that iNOS levels were higher in tumor specimens with lymph node or distant metastasis than those without metastasis. It was suggested that NO may be regarded as a novel biological marker in cancer prognosis[65]. Both total NO expression and iNOS activity were reported to promote tumor progression and might explain the association between $\mathrm{NO}$ and tumor staging[66]. Additionally, expression of iNOS is one of the potential mechanisms by which $\mathrm{NO}$ can promote tumor growth and metastasis, being an important stimulant of angiogenesis[67]. In the present study, total serum lipase activity was significantly up-regulated among CRC patients, an observation reported elsewhere[68] and added that this up-regulation was not associated with evidence of pancreatitis. In addition, metastatic group showed more significant up-regulation of lipase activity. This action is in agreement with the reported results of Munoz-Perez et al.,[69] who observed an increased serum lipase in patients with massive abdominal metastases. There are several possible mechanisms explaining the increase in serum lipase level in CRC patients, such as the presence of an unusual lipase isoenzyme, a decrease in the clearance or rate of inactivation of lipase in the circulation, the persistence of lipase in blood after complexation with plasma protein, or the direct production of lipase from the neoplastic masses[68,70]. In our study, the treatment significantly decreased lipase activity than pre-treatment values, an indication that lipase changes are primarily responsive to chemotherapy. Some studies have illustrated that the autocrine effect of lipase on macrophage activated tumor necrosis factor alpha (TNF- $\alpha$ ) and additional induction on interferon gamma (IFN- $\gamma$ ) results in a well-known synergistic effect of IFN- $\gamma$ and TNF- $\alpha$ on macrophage NO production, which suggests the possibility that lipase may act with IFN- $\gamma$ to increase macrophage NO formation[71]. Activation of nitric oxide synthase (NOS) gene expression has been reported to occur after macrophage stimulation with IFN- $\gamma$ and lipase[72]. This is why we studied this group of contributing players in CRC diagnosis and treatment outcomes. On the other hand, because a metastatic group was opted in the study, AFP levels were checked in all groups. This was done to see if AFP is elevated in early diagnosed secondary HCC or not. The results revealed that its level was not changed to significant levels in all studied groups in comparison to normal group. This is possibly due to the poor sensitivity of AFP in early born $\mathrm{HCC}$, as it is well known that its sensitivity is only around $60 \%[73]$.

\section{Conclusions}

It seems that angiogenesis mediators (VEGF, NO and TL) shared CEA and CA19.9 in both diagnosis and prognosis of CRC. They were concomitantly elevated in local and metastatic invasion, with obvious up-regulation in metastasis. However, AFP seems to be not significantly affected in all groups, considering $\mathrm{HCC}$ as a secondary metastatic type after CRC. Response to chemotherapy was striking in TL 
rather than VEGF and NO. This substantiates a new role, which is the anti-proangiogenic potential of common 5-FU/LV protocol as an additional pathway in controlling CRC in cytotoxic doses. VEGF, NO persistent elevations among metastatic individuals after adjuvant therapy is an additional tool predicting recurrence, while TL is not reliable recurrence predictor, as it is affected by chemotherapy, which means that mostly it may be accommodated and escapes contribution into recurrence. AFP level was not changed in secondary metastatic hepatocellular carcinoma (HCC), seemingly, it rises only in primary HCCs The study also necessitates the significance of controlling NO expression and suppressing inflammation as adjuvant modality in CRC therapeutic strategies and possibly claim for selective angiogenic inhibitors to improve chemotherapy outcomes.

\section{ACKNOWLEDGEMENTS}

The histological examinations were done at Histopathology Department at University Hospital of Mansura University, Egypt, under supervision of Pro Adel A. Zalata, professor of Pathology at the same Department.

\section{REFERENCES}

[1] W. Khafagy, EI-Ghazaly, M, El-Shobaky, MT and Khafagy, M Colorectal Cancer in Egypt - Does it Differ?. Semin Oncol 32 (2000) 3-10

[2] H. T. Lynch, and A. de la Chapelle, Hereditary colorectal cancer. N Engl J Med 348 (2003) 919-32

[3] R. J. Mitchell, D. Brewster, H. Campbell, M. E. Porteous, A. H. Wyllie, C. C. Bird, and M. G. Dunlop, Accuracy of reporting of family history of colorectal cancer. Gut 53 (2004) $291-5$

[4] D. A. Lieberman, S. Prindiville, D. G. Weiss, and W. Willett, Risk factors for advanced colonic neoplasia and hyperplastic polyps in asymptomatic individuals. Jama 290 (2003) 2959-67

[5] A. Russo, S. Franceschi, C. La Vecchia, L. Dal Maso, M. Montella, E. Conti, A. Giacosa, F. Falcini, and E. Negri, Body size and colorectal-cancer risk. Int J Cancer 78 (1998) $161-5$

[6] C. A. Doubeni, T. S. Field, D. S. Buist, E. J. Korner, C. Bigelow, L. Lamerato, L. Herrinton, V. P. Quinn, G. Hart, M. C. Hornbrook, J. H. Gurwitz, and E. H. Wagner, Racial differences in tumor stage and survival for colorectal cancer in an insured population. Cancer 109 (2007) 612-20

[7] A. Rullier, and C. Laurent, [Recommendations for clinical practice. Therapeutic choices for rectal cancer. What quality criteria are important for surgical excision of rectal cancer?]. Gastroenterol Clin Biol 31 Spec No 1 (2007) 1S34-51, 1S91-5

[8] M. Vermaas, F. T. Ferenschild, C. Verhoef, J. J. Nuyttens, A. W. Marinelli, T. Wiggers, W. J. Kirkels, A. M. Eggermont, and J. H. de Wilt, Total pelvic exenteration for primary locally advanced and locally recurrent rectal cancer. Eur $\mathbf{J}$ Surg Oncol 33 (2007) 452-8

[9] W. Zhang, M. Gordon, and H. J. Lenz, Novel approaches to treatment of advanced colorectal cancer with anti-EGFR monoclonal antibodies. Ann Med 38 (2006) 545-51

[10] W. S. Liao, A. R. Conn, and J. M. Taylor, Changes in rat alpha 1-fetoprotein and albumin mRNA levels during fetal and neonatal development. J Biol Chem 255 (1980) 10036-9

[11] M. F. Yuen, C. C. Cheng, I. J. Lauder, S. K. Lam, C. G. Ooi, and C. L. Lai, Early detection of hepatocellular carcinoma increases the chance of treatment: Hong Kong experience. Hepatology 31 (2000) 330-5

[12] Y. H. Ding, X. D. Luan, J. Li, J.A. Rafols, M. Guthinkonda, F. G. Diaz, and Y. Ding, Exercise-induced overexpression of angiogenic factors and reduction of ischemia/reperfusion injury in stroke. Curr Neurovasc Res 1 (2004) 411-20

[13] R. M. Kraus, H. W. Stallings, 3rd, R. C. Yeager, and T. P. Gavin, Circulating plasma VEGF response to exercise in sedentary and endurance-trained men. J Appl Physiol 96 (2004) 1445-50

[14] J. Folkman, Tumor angiogenesis: therapeutic implications. N Engl J Med 285 (1971) 1182-6

[15] C. J. Wray, H. L. Rilo, and S. A. Ahmad, Colon cancer angiogenesis and antiangiogenic therapy. Expert Opin Investig Drugs 13 (2004) 631-41

[16] B. M. Prior, H.T. Yang, and R.L. Terjung, What makes vessels grow with exercise training? J Appl Physiol 97 (2004) $1119-28$

[17] Y. H. Kim, K. J. Woo, J. H. Lim, S. Kim, T. J. Lee, E. M. Jung, J. M. Lee, J. W. Park, and T. K. Kwon, 8-Hydroxyquinoline inhibits iNOS expression and nitric oxide production by down-regulating LPS-induced activity of NF-kappaB and C/EBPbeta in Raw 264.7 cells. Biochem Biophys Res Commun 329 (2005) 591-7

[18] L. J. Hofseth, S. Saito, S. P. Hussain, M. G. Espey, K. M. Miranda, Y. Araki, C. Jhappan, Y. Higashimoto, P. He, S. P. Linke, M. M. Quezado, I. Zurer, V. Rotter, D. A. Wink, E. Appella, and C. C. Harris, Nitric oxide-induced cellular stress and $\mathrm{p} 53$ activation in chronic inflammation. Proc Natl Acad Sci U S A 100 (2003) 143-8

[19] D. A. Wink, K. S. Kasprzak, C. M. Maragos, R. K. Elespuru, M. Misra, T. M. Dunams, T. A. Cebula, W. H. Koch, A. W. Andrews, J. S. Allen, and et al., DNA deaminating ability and genotoxicity of nitric oxide and its progenitors. Science 254 (1991) 1001-3

[20] D. C. Jenkins, I. G. Charles, L. L. Thomsen, D. W. Moss, L. S. Holmes, S. A. Baylis, P. Rhodes, K. Westmore, P. C. Emson, and S. Moncada, Roles of nitric oxide in tumor growth. Proc Natl Acad Sci U S A 92 (1995) 4392-6

[21] S. Ambs, W. G. Merriam, M. O. Ogunfusika, W. P. Bennett, N. Ishibe, S. P. Hussain, E. E. Tzeng, D. A. Geller, T. R. Billiar, and C. C. Harris, p53 and vascular endothelial growth factor regulate tumor growth of NOS2-expressing human carcinoma cells. Nat Med 4 (1998) 1371-6

[22] S. Ambs, M. O. Ogunfusika, W. G. Merriam, W. P. Bennett, T. R. Billiar, and C. C. Harris, Up-regulation of inducible 
nitric oxide synthase expression in cancer-prone p53 knockout mice. Proc Natl Acad Sci U S A 95 (1998) 8823-8

[23] J. Li, T. R. Billiar, R. V. Talanian, and Y. M. Kim, Nitric oxide reversibly inhibits seven members of the caspase family via S-nitrosylation. Biochem Biophys Res Commun 240 (1997) 419-24

[24] M. E. Lowe, The triglyceride lipases of the pancreas. J Lipid Res 43 (2002) 2007-16

[25] M. Takahashi, Y. Hiyama, M. Yokoyama, S. Yu, Y. Hu, K. Melford, A. Bensadoun, and I. J. Goldberg, In vivo arterial lipoprotein lipase expression augments inflammatory responses and impairs vascular dilatation. Arterioscler Thromb Vasc Biol 28 (2008) 455-62

[26] C. W. Hendrickse, S. Radley, I. A. Donovan, M. R. Keighley, and J. P. Neoptolemos, Activities of phospholipase A2 and diacylglycerol lipase are increased in human colorectal cancer. Br J Surg 82 (1995) 475-8

[27] C. Wittekind, C. C. Compton, F. L. Greene, and L. H. Sobin, TNM residual tumor classification revisited. Cancer 94 (2002) 2511-6

[28] M. J. O'Connell, J. A. Mailliard, M. J. Kahn, J. S. Macdonald, D. G. Haller, R. J. Mayer, and H. S. Wieand, Controlled trial of fluorouracil and low-dose leucovorin given for 6 months as postoperative adjuvant therapy for colon cancer. J Clin Oncol 15 (1997) 246-50

[29] D. E. DuBois D, A formula to estimate the approximate surface area if height and weight be known. Arch Intern Medicine. 17 (1916) 863-71

[30] Y. Wang, J. Moss, and R. Thisted, Predictors of body surface area. J Clin Anesth 4 (1992) 4-10

[31] J. Lin, and H. Ju, Electrochemical and chemiluminescent immunosensors for tumor markers. Biosens Bioelectron 20 (2005) 1461-70

[32] K. Lee, Kim, KI and Lee, KP, Development of Enzyme Immuno Assay Kit for Alpha Feto protein. Korean J. Immunol 19 (1997) 455-461

[33] S. L. Sheng, S. H. Bao, G. Huang, and L. M. Wang, Development of time-resolved immunofluorometric assays for vascular endothelial growth factor and application on plasma of patients with gastric tumours. Clin Exp Immunol 151 (2008) 459-66

[34] K. Miranda, Espey, MG and Wink, DA A rapid, simple spectrophotometric method for simultaneous detection of nitrate and nitrite. Nitric Oxide 5 (2001) 62-71

[35] B. Graca, C. Lunet, A. S. Coelho, G. Monteiro, P. Freire, A. Speidel, and L. Carvalho, [Angiogenesis and cancer: from biopathology to therapy]. Acta Med Port 17 (2004) 76-93

[36] W. G. Hu, J. W. Li, B. Feng, M. Beveridge, F. Yue, A. G. Lu, J. J. Ma, M. L. Wang, Y. Guo, X. L. Jin, and M. H. Zheng, Vascular endothelial growth factors $\mathrm{C}$ and $\mathrm{D}$ represent novel prognostic markers in colorectal carcinoma using quantitative image analysis. Eur Surg Res 39 (2007) 229-38

[37] N. H. Fernando, and H. I. Hurwitz, Targeted therapy of colorectal cancer: clinical experience with bevacizumab. Oncologist 9 Suppl 1 (2004) 11-8
[38] F. F. Kabbinavar, J. Schulz, M. McCleod, T. Patel, J. T. Hamm, J. R. Hecht, R. Mass, B. Perrou, B. Nelson, and W. F. Novotny, Addition of bevacizumab to bolus fluorouracil and leucovorin in first-line metastatic colorectal cancer: results of a randomized phase II trial. J Clin Oncol 23 (2005) 3697-705

[39] J. Y. Wang, C. Y. Lu, K. S. Chu, C. J. Ma, D. C. Wu, H. L. Tsai, F. J. Yu, and J. S. Hsieh, Prognostic significance of preand postoperative serum carcinoembryonic antigen levels in patients with colorectal cancer. Eur Surg Res 39 (2007) 245-50

[40] M. J. Duffy, Clinical uses of tumor markers: a critical review. Crit Rev Clin Lab Sci 38 (2001) 225-62

[41] M. Grotowski, M. Maruszynski, and W. Piechota, [Usefulness of preoperative assay CEA and CA 19-9 in colorectal cancer patients]. Pol Merkur Lekarski 11 (2001) 476-9

[42] R. C. Bast, Jr., P. Ravdin, D. F. Hayes, S. Bates, H. Fritsche, Jr., J. M. Jessup, N. Kemeny, G. Y. Locker, R. G. Mennel, and M. R. Somerfield, 2000 update of recommendations for the use of tumor markers in breast and colorectal cancer: clinical practice guidelines of the American Society of Clinical Oncology. J Clin Oncol 19 (2001) 1865-78

[43] M. J. Duffy, A. van Dalen, C. Haglund, L. Hansson, R. Klapdor, R. Lamerz, O. Nilsson, C. Sturgeon, and O. Topolcan, Clinical utility of biochemical markers in colorectal cancer: European Group on Tumour Markers (EGTM) guidelines. Eur J Cancer 39 (2003) 718-27

[44] W. S. Wang, J. K. Lin, T. J. Chiou, J. H. Liu, F. S. Fan, C. C. Yen, T. C. Lin, J. K. Jiang, S. H. Yang, H. S. Wang, and P. M. Chen, CA19-9 as the most significant prognostic indicator of metastatic colorectal cancer. Hepatogastroenterology 49 (2002) 160-4

[45] D. Gholam, S. Giacchetti, C. Brezault-Bonnet, M. Bouchahda, D. Hauteville, R. Adam, B. Ducot, O. Ghemard, F. Kustlinger, C. Jasmin, and F. Levi, Chronomodulated irinotecan, oxaliplatin, and leucovorin-modulated 5-Fluorouracil as ambulatory salvage therapy in patients with irinotecan- and oxaliplatin-resistant metastatic colorectal cancer. Oncologist 11 (2006) 1072-80

[46] H. Michiko, Kenjiro, K, Kenji, K , Osamu, J, Masami, I , Shoichi, H, Takanobu, Y, Takeo, T and Seiji, G Hepatic Metastases from Alpha-Fetoprotein Producing Colorectal Cancer That Responded Remarkably to Transcatheter Arterial Chemo-embolization. Japanese Journal of Cancer and Chemotherapy 29 (2002) 2366-2369

[47] V. Hanrahan, M. J. Currie, S. P. Gunningham, H. R. Morrin, P. A. Scott, B. A. Robinson, and S. B. Fox, The angiogenic switch for vascular endothelial growth factor (VEGF)-A, VEGF-B, VEGF-C, and VEGF-D in the adenoma-carcinoma sequence during colorectal cancer progression. J Pathol 200 (2003) 183-94

[48] R. E. Frank, T. J. Saclarides, S. Leurgans, N. J. Speziale, E. A. Drab, and D. B. Rubin, Tumor angiogenesis as a predictor of recurrence and survival in patients with node-negative colon cancer. Ann Surg 222 (1995) 695-9

[49] G. Galizia, E. Lieto, F. Ferraraccio, M. Orditura, F. De Vita, P. Castellano, V. Imperatore, C. Romano, F. Ciardiello, B. Agostini, and C. Pignatelli, Determination of molecular 
marker expression can predict clinical outcome in colon carcinomas. Clin Cancer Res 10 (2004) 3490-9

[50] J. C. Lee, N. H. Chow, S. T. Wang, and S. M. Huang, Prognostic value of vascular endothelial growth factor expression in colorectal cancer patients. Eur J Cancer 36 (2000) 748-53

[51] P. Mysliwiec, Z. Piotrowski, B. Zalewski, A. Kuklinski, and K. Pawlak, Plasma VEGF-A and its soluble receptor R1 correlate with the clinical stage of colorectal cancer. Rocz Akad Med Bialymst 49 Suppl 1 (2004) 85-7

[52] F. Kabbinavar, H. I. Hurwitz, L. Fehrenbacher, N. J. Meropol, W. F. Novotny, G. Lieberman, S. Griffing, and E. Bergsland, Phase II, randomized trial comparing bevacizumab plus fluorouracil (FU)/leucovorin (LV) with FU/LV alone in patients with metastatic colorectal cancer. J Clin Oncol 21 (2003) 60-5

[53] M. P. Morelli, A. M. Brown, T. M. Pitts, J. J. Tentler, F. Ciardiello, A. Ryan, J. M. Jurgensmeier, and S. G. Eckhardt, Targeting vascular endothelial growth factor receptor-1 and -3 with cediranib (AZD2171): effects on migration and invasion of gastrointestinal cancer cell lines. Mol Cancer Ther 8 (2009) 2546-58

[54] A. Ooyama, T. Oka, H. Y. Zhao, M. Yamamoto, S. Akiyama, and M. Fukushima, Anti-angiogenic effect of 5-Fluorouracil-based drugs against human colon cancer xenografts. Cancer Lett 267 (2008) 26-36

[55] P. Albertsson, B. Lennernas, and K. Norrby, Low-dose continuous 5-fluorouracil infusion stimulates VEGF-A-mediated angiogenesis. Acta Oncol 48 (2009) $418-25$

[56] S. S. Mirvish, Role of N-nitroso compounds (NOC) and $\mathrm{N}$-nitrosation in etiology of gastric, esophageal, nasopharyngeal and bladder cancer and contribution to cancer of known exposures to NOC. Cancer Lett 93 (1995) $17-48$

[57] E. E. Mannick, L. E. Bravo, G. Zarama, J. L. Realpe, X. J. Zhang, B. Ruiz, E. T. Fontham, R. Mera, M. J. Miller, and P. Correa, Inducible nitric oxide synthase, nitrotyrosine, and apoptosis in Helicobacter pylori gastritis: effect of antibiotics and antioxidants. Cancer Res 56 (1996) 3238-43

[58] P. L. Majano, C. Garcia-Monzon, M. Lopez-Cabrera, E. Lara-Pezzi, E. Fernandez-Ruiz, C. Garcia-Iglesias, M. J. Borque, and R. Moreno-Otero, Inducible nitric oxide synthase expression in chronic viral hepatitis. Evidence for a virus-induced gene upregulation. J Clin Invest 101 (1998) $1343-52$

[59] M. Jaiswal, N. F. LaRusso, R. A. Shapiro, T. R. Billiar, and G. J. Gores, Nitric oxide-mediated inhibition of DNA repair potentiates oxidative DNA damage in cholangiocytes. Gastroenterology 120 (2001) 190-9

[60] Singer, II, D. W. Kawka, S. Scott, J. R. Weidner, R. A. Mumford, T. E. Riehl, and W. F. Stenson, Expression of inducible nitric oxide synthase and nitrotyrosine in colonic epithelium in inflammatory bowel disease. Gastroenterology 111 (1996) 871-85
[61] G. Montrucchio, E. Lupia, A. de Martino, E. Battaglia, M. Arese, A. Tizzani, F. Bussolino, and G. Camussi, Nitric oxide mediates angiogenesis induced in vivo by platelet-activating factor and tumor necrosis factor-alpha. Am J Pathol 151 (1997) 557-63

[62] P. Lejeune, P. Lagadec, N. Onier, D. Pinard, H. Ohshima, and J. F. Jeannin, Nitric oxide involvement in tumor-induced immunosuppression. J Immunol 152 (1994) 5077-83

[63] O. Fantappie, E. Masini, I. Sardi, L. Raimondi, D. Bani, M. Solazzo, A. Vannacci, and R. Mazzanti, The MDR phenotype is associated with the expression of COX-2 and iNOS in a human hepatocellular carcinoma cell line. Hepatology 35 (2002) 843-52

[64] X. P. Hao, T. G. Pretlow, J. S. Rao, and T. P. Pretlow, Inducible nitric oxide synthase (iNOS) is expressed similarly in multiple aberrant crypt foci and colorectal tumors from the same patients. Cancer Res 61 (2001) 419-22

[65] A. Franchi, O. Gallo, M. Paglierani, I. Sardi, L. Magnelli, E. Masini, and M. Santucci, Inducible nitric oxide synthase expression in laryngeal neoplasia: correlation with angiogenesis. Head Neck 24 (2002) 16-23

[66] S. Mocellin, V. Bronte, and D. Nitti, Nitric oxide, a double edged sword in cancer biology: searching for therapeutic opportunities. Med Res Rev 27 (2007) 317-52

[67] K. M. Ropponen, J. K. Kellokoski, P. K. Lipponen, M. J. Eskelinen, L. Alanne, E. M. Alhava, and V. M. Kosma, Expression of inducible nitric oxide synthase in colorectal cancer and its association with prognosis. Scand J Gastroenterol 35 (2000) 1204-11

[68] J. G. Donnelly, D. S. Ooi, B. F. Burns, and R. Goel, Chronic increased serum lipase without evidence of pancreatitis: tumor-derived lipase? Clin Chem 42 (1996) 462-4

[69] M. Munoz-Perez, D. Sarrion-Pelous, J. Jimenez-Jimenez, P. Martinez-Montiel, and M. Gallego-Valdes, Chronic increased serum lipase in a patient with suspected pancreatic adenocarcinoma. Clin Chem 43 (1997) 191-3

[70] R. S. Kota, C. V. Ramana, F. A. Tenorio, R. I. Enelow, and J. C. Rutledge, Differential effects of lipoprotein lipase on tumor necrosis factor-alpha and interferon-gamma-mediated gene expression in human endothelial cells. J Biol Chem 280 (2005) 31076-84

[71] H. Nguyen, C. V. Ramana, J. Bayes, and G. R. Stark, Roles of phosphatidylinositol 3-kinase in interferon-gammadependent phosphorylation of STAT1 on serine 727 and activation of gene expression. J Biol Chem 276 (2001) 33361-8

[72] G. R. Stark, I. M. Kerr, B. R. Williams, R. H. Silverman, and R. D. Schreiber, How cells respond to interferons. Annu Rev Biochem 67 (1998) 227-64.

[73] M. Sherman, K. M. Peltekian, and C. Lee, Screening for hepatocellular carcinoma in chronic carriers of hepatitis B virus: incidence and prevalence of hepatocellular carcinoma in a North American urban population. Hepatology 22 (1995) $432-8$ 